\title{
Barriers to Obesity Management: Patient and Physician Factors
}

Tae Nyun Kim*

Department of Internal Medicine, Cardiovascular and Metabolic Disease Center, Inje University College of Medicine, Busan, Korea
Received November 20, 2020

Reviewed December 3, 2020

Accepted December 15, 2020

*Corresponding author

Tae Nyun Kim

https://orcid.org/0000-0001-6568-2469

Department of Internal Medicine, Cardiovascular and Metabolic Disease Center, Inje University College of

Medicine, 875 Haeun-daero, Haeundae-gu, Busan 48108, Korea

Tel: +82-51-797-2060

Fax: +82-51-797-2070

E-mail: kimtn031@gmail.com
The prevalence of obesity is increasing worldwide. Obesity is a chronic, relapsing, and progressive disease associated with serious complications and comorbidities. ${ }^{1-3}$ Moreover, it has been associated with the increased risk of mortality due to cardiovascular diseases and most cancers. ${ }^{4}$ In addition, the effects of weight reduction on alleviating obesity-related comorbidities and risk factors have been well documented. ${ }^{4}$

Obesity treatment guidelines from various academic societies, including the Korean Society for the Study of Obesity, recommend lifestyle interventions along with pharmacotherapy if the response to dietary changes, physical activity, and behavioral changes is insufficient to reach or maintain the recommended goal of 5\%-10\% loss of body weight. ${ }^{4-6}$ Bariatric surgery should be considered for people with severe degree of obesity or obesity-related comorbidities. ${ }^{4-6}$ Despite the availability of these guidelines, a minority of people with obesity $(\mathrm{PwO})$ receive clinically proven lifestyle, pharmacological, and/or surgical interventions. ${ }^{7,8}$ In other words, $\mathrm{PwO}$ experience variable care. ${ }^{7}$ In practice, nearly $25 \%$ of $\mathrm{PwO}$ achieve an annual weight loss $\geq 5 \%$.

The unsatisfactory outcomes of obesity treatment reflect a failure of both patients and physicians' initiating or maintaining the nec- essary therapies. The first step to successful management of obesity comprises identifying and understanding the barriers to the standards of care during self-management and clinician interventions. Although barriers differ by treatment modality, this review focuses on common barriers that should be identified and addressed for weight loss as well as prevention of further weight gain. The aim of this review is to summarize the existing knowledge on the barriers of obesity management from the perspectives of both patients and physicians from the perspectives of both patients and physicians (Fig. 1).

\section{PATIENT FACTORS}

Lack of recognition of obesity as a chronic and relapsing disease

According to the Awareness, Care and Treatment in Obesity MaNagement - an International Observation (ACTION-IO) study, most PwO and healthcare professionals (HCPs) agree that obesity is a chronic disease. ${ }^{7}$ The results from South Korea indicated that, compared to HCPs, a higher proportion of $\mathrm{PwO}$ consider obesity to have a large effect on overall health. ${ }^{8}$ In addition, $78 \%$ of 


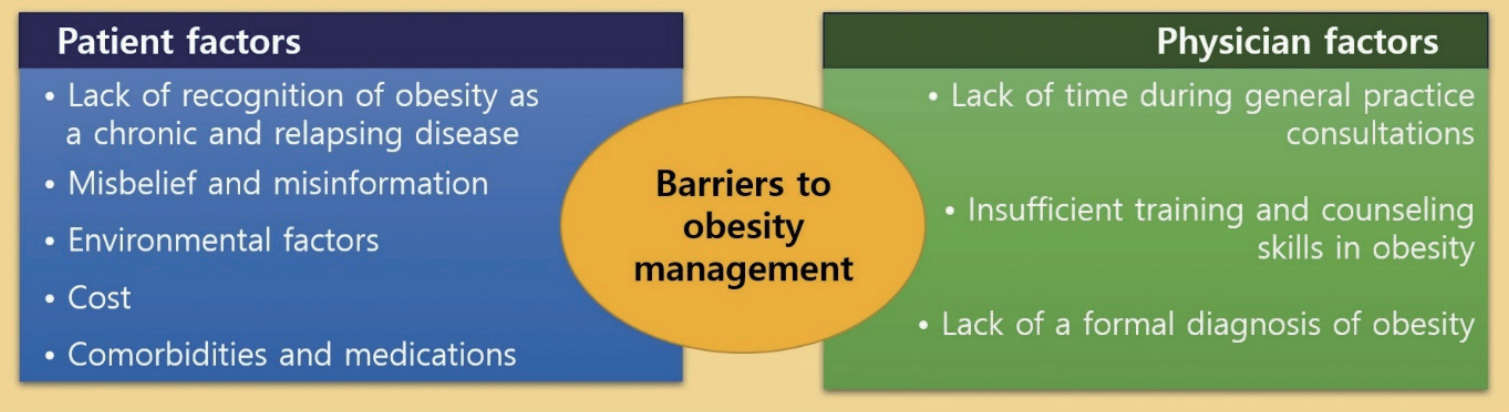

Figure 1. Patient and physician factors associated with barriers to obesity management.

PwO stated that they had made at least one serious weight loss effort in the past. ${ }^{8}$ Nonetheless, only $12 \%$ of $\mathrm{PwO}$ reported a loss of at least $10 \%$ of body weight over the past 3 years. Moreover, less than half of the population maintained the weight loss for at least 1 year. ${ }^{8}$ The low success rate can be partially attributed to the lack of preparedness of $\mathrm{PwO}$ to adhere to persistent treatment for maintaining weight loss. If no long-term treatment strategies exist to prevent weight regain, weight loss might be meaningless. In addition, long-term compliance with obesity medications is very low: the 1 -year and 2-year persistence rates are $<10 \%$ and $2 \%$, respectively. ${ }^{9}$ Despite successful bariatric surgery, patients can regain weight if they fail to implement successful strategies to prevent weight regain. ${ }^{9}$ Therefore, $\mathrm{PwO}$ need to recognize that obesity is a chronic disease prone to relapse to fully appreciate the importance of longterm management.

\section{Misbelief and misinformation about obesity management}

PwO hold a wide range of attitudes and beliefs about obesity and its treatment. According to the ACTION-IO results from South Korea, ${ }^{8} 48 \%$ of $\mathrm{PwO}$ believe they could lose weight if they were determined. Rather than seeking advice from HCPs, they prefer alternative sources of information on weight management, such as the internet, family and friends, television programs, and smartphone applications. ${ }^{8}$ These sources are likely to be ineffective and might even pose significant health risks.

\section{Environmental factors}

Culture and family influence the beliefs, attitudes, knowledge, and behaviors of an individual toward obesity self-management. ${ }^{9}$ Dieting is common, especially among women. Participation in ac- tivities associated with food and alcohol consumption may be linked to personal behaviors. For example, it might be difficult to overcome overeating during social gatherings, and social and professional obligations can sabotage patient efforts. Furthermore, a family is a dynamic system that influences important risk factors for obesity in children and adolescents. In particular, parental work schedules and family eating habits were the most frequently cited barriers to healthy eating and exercise among studies of obese adolescents. ${ }^{10}$ For adults, the family as an environmental factor of obesity can play a role in maintaining weight loss as well as reducing body weight. Successful weight loss may depend upon family functioning or finding a support system within and/or outside the family. ${ }^{11}$ Therefore, successful adherence to long-term lifestyle changes necessitates a strong support network of family, friends, or peers.

\section{Cost}

Cost of treatment is a significant barrier to obesity management, particularly for patients with a low socioeconomic status in developed countries. ${ }^{12}$ Other major obstacles include the high cost of a healthy diet and the unaffordability of membership in commercial weight loss programs and gymnasiums. ${ }^{9}$ In addition, unlike medical treatments for other chronic diseases, obesity medications are generally not reimbursed by health care systems. However, the ACTION-IO study conducted in South Korea reported that fewer $\mathrm{PwO}$ consider their financial status as a barrier to weight loss compared to HCPs. ${ }^{8}$ Nevertheless, these factors can hinder weight management and interventions and must be acknowledged.

\section{Comorbidities and medications}

Multiple chronic conditions, including mental health problems, 
sleep disorders, cardiopulmonary diseases, or pain, can impose limitations on the physical activity of all patients. People with multiple comorbidities frequently experience barriers to obesity self-management. Obesity also is associated with several endocrine diseases including hypothyroidism, polycystic ovarian syndrome, Cushing's syndrome, central hypothyroidism, and hypothalamic disorders. However, endocrine function testing cannot be justified unless there is clinical evidence to support a diagnosis other than simple obesity. Furthermore, several commonly used drugs cause iatrogenic weight gain, leading to exacerbation of comorbidities and non-compliance with therapies. ${ }^{13}$

\section{PHYSICIAN FACTORS}

\section{Lack of time during general practice consultations}

Lack of time with patients is one of the most frequently encountered barriers to obesity management. HCPs cite limited appointment time as the principal reason for not discussing weight management with their patients, similar to the results of the ACTIONIO study from South Korea. ${ }^{8}$ Therefore, certain administrative barriers must be alleviated to facilitate longer appointment times globally, but particularly in South Korea.

\section{Insufficient training and counseling skills for obesity}

HCPs perceive several barriers that prevent them from aligning their clinical practice with the current recommendations, and lack of training is one of the key barriers to obesity management. Obesity education for HCPs includes diverse fields, such as diet, nutrition, exercise, behavior therapy, and medication. Nonetheless, physicians find it difficult to provide effective weight loss counseling for PwO, which is a probably a consequence of lack of basic knowledge on exercise, nutrition, and applied clinical experience from medical schools and residency training programs. ${ }^{14}$ Moreover, a review of the U.S. Medical Licensing Examinations reported on the rare inclusion of obesity-specific content in examinations. ${ }^{15}$ Most medical school curricula in Korea do not encompass sufficient obesity education, including adequate nutrition education for medical students. Considering the impact of counseling delivered by HCPs on weight loss behaviors, medical schools must adequately address obesity education in their curricula.

\section{Lack of a formal diagnosis of obesity}

Despite its increased recognition as a chronic disease, obesity remains greatly underdiagnosed. According to the South Korean ACTION-IO study, 50\% of PwO consider themselves obese. Furthermore, 55\% report receiving a formal diagnosis. A substantially smaller rate of South Korean $\mathrm{PwO}$ (22\% of $\mathrm{PwO}$ ) had been diagnosed with obesity through weight management discussion with an $\mathrm{HCP}$ compared to the global proportion. ${ }^{8} \mathrm{PwO}$ who receive an early diagnosis could experience fewer complications or other chronic diseases. Therefore, physicians should proactively screen for obesity and initiate discussions on obesity management.

In conclusion, obesity is a complex disease with multifactorial barriers to management. Notwithstanding the increasing perception that obesity is a chronic and progressive disease, management is much weaker than that of other chronic diseases, such as type 2 diabetes and hypertension. Therefore, obesity management must be a persistent effort for both $\mathrm{PwO}$ and physicians. Identifying and addressing barriers to obesity management are essential before patients can adopt necessary lifestyle changes and adhere to therapies. Further research should focus on the degree of weight loss and the development of an obesity program.

\section{CONFLICTS OF INTEREST}

The author declares no conflict of interest.

\section{REFERENCES}

1. Prospective Studies Collaboration, Whitlock G, Lewington S, Sherliker P, Clarke R, Emberson J, et al. Body-mass index and cause-specific mortality in 900000 adults: collaborative analyses of 57 prospective studies. Lancet 2009;373:1083-96.

2. GBD 2015 Obesity Collaborators, Afshin A, Forouzanfar MH, Reitsma MB, Sur P, Estep K, et al. Health effects of overweight and obesity in 195 countries over 25 years. $\mathrm{N}$ Engl J Med 2017;377:13-27.

3. Bray GA, Kim KK, Wilding JP; World Obesity Federation. Obesity: a chronic relapsing progressive disease process. A position statement of the World Obesity Federation. Obes Rev 2017;18:715-23. 
4. Jensen MD, Ryan DH, Apovian CM, Ard JD, Comuzzie AG, Donato KA, et al. 2013 AHA/ACC/TOS guideline for the management of overweight and obesity in adults: a report of the American College of Cardiology/American Heart Association Task Force on Practice Guidelines and The Obesity Society. J Am Coll Cardiol 2014;63(25 Pt B):2985-3023.

5. Yumuk V, Tsigos C, Fried M, Schindler K, Busetto L, Micic D, et al. European Guidelines for Obesity Management in Adults. Obes Facts 2015;8:402-24.

6. Seo MH, Lee WY, Kim SS, Kang JH, Kang JH, Kim KK, et al. 2018 Korean Society for the Study of Obesity Guideline for the Management of Obesity in Korea. J Obes Metab Syndr 2019;28:40-5.

7. Caterson ID, Alfadda AA, Auerbach P, Coutinho W, Cuevas A, Dicker D, et al. Gaps to bridge: misalignment between perception, reality and actions in obesity. Diabetes Obes Metab 2019;21:1914-24.

8. Lim S, Oh B, Lee SH, Kim YH, Ha Y, Kang JH. Perceptions, attitudes, behaviors, and barriers to effective obesity care in south Korea: results from the ACTION-IO Study. J Obes
Metab Syndr 2020;29:133-42.

9. Mauro M, Taylor V, Wharton S, Sharma AM. Barriers to obesity treatment. Eur J Intern Med 2008;19:173-80.

10. Porter JS, Bean MK, Gerke CK, Stern M. Psychosocial factors and perspectives on weight gain and barriers to weight loss among adolescents enrolled in obesity treatment. J Clin Psychol Med Settings 2010;17:98-102.

11. Frankle RT. Obesity a family matter: creating new behavior. J Am Diet Assoc 1985;85:597-602.

12. Sobal J, Stunkard AJ. Socioeconomic status and obesity: a review of the literature. Psychol Bull 1989;105:260-75.

13. Ness-Abramof R, Apovian CM. Drug-induced weight gain. Timely Top Med Cardiovasc Dis 2005;9:E31.

14. Lee SY. Obesity education in medical school curricula in Korea. J Obes Metab Syndr 2018;27:35-8.

15. Kushner RF, Butsch WS, Kahan S, Machineni S, Cook S, Aronne LJ. Obesity coverage on medical licensing examinations in the United States: what is being tested? Teach Learn Med 2017;29:123-8. 